\title{
Krzysztof Miecznikowski
}

\section{Foreword}

DOI: 10.1515/cti-2019-2005

This volume presents the proceedings of the $14^{\text {th }}$ European Conference on Research in Chemical Education (ECRICE 2018) that was a continuation of successful previous meetings in Barcelona (Spain 2016), Jyväskylä, (Finland 2014), Rome (Italy 2012), Krakow (Poland 2010) and Istanbul, (Turkey 2008). The conference held in Warsaw, Poland on September $2^{\text {nd }}-6^{\text {th }}, 2018$ and organized by the Faculty of Chemistry of the University of Warsaw and the Division of Chemical Education of European Association of Chemical Molecular Sciences (EuCheMS).

The subject of conference covered the chemical education of students with the disabilities, chemical education of talented students, chemistry in STEM education, history of chemistry education, ICT in chemistry education, lifelong chemical education, as well as nature of science, outdoor chemical education, professional development of chemistry teachers, novel trends in chemistry education research. The conference provided an overview of the state of the arte in the chemical education area, exhibited the lastest achievements and important directions for the future in this field. Moreover, during conference one of the symposiums devoted to the memory of Professor Alex H. Johnstone (1930-2017) outstanding scientist working in the research of chemical education and related subjects. All sessions were well attended.

The scientific program consisted of four plenary lectures delivered by internationally renowned experts, one symposium dedicated in Memory of Professor Alex H. Johnstone, four workshops and 63 oral contributions as well 38 posters presentations covering some of the most important and exciting topics in chemical education. The conference was attended by 95 participants from 11 countries: Australia, Austria, Brazil, Costa Rica, Czech Republic, Finland, France, Germany, Greece, Hungary, Lithuania, Estonia, Israel, Ireland, Malta, New Zealand, Norway, Poland, Portugal, Republic of Macedonia, Russia, Scotland, Serbia, Slovakia, Slovenia, Spain, Sweden, Turkey, United Kingdom, and United States of America.

The special issue of Chemistry Teacher International contains a selection of 9 papers presented during the meeting. The organizers and Guest Editors would like kindly to thank all those who attended the conference and helped to continue the tradition of the European Conference on Research in Chemical Education as well as to all the authors, who submitted high quality articles and the reviewers for their contributions to assess and improve the submitted manuscripts in order to keep the high publication standards of the journal.

Krzysztof Miecznikowski, Guest Editor 